\title{
Upaya Peningkatkan Status Pengetahuan Kesehatan Gigi dan Mulut pada Masyarakat dengan Metode Penyuluhan FlipChart dan Video di Desa Lanna
}

\author{
1Sari Aldilawati, ${ }^{2}$ Muhammad Fajrin Wijaya, ${ }^{3}$ Nur Rahmah Hasanuddin \\ 1,2,3Fakultas Kedokteran Gigi, Universitas Muslim Indonesia \\ Korespondensi: sharyaldila@umi.ac.id
}

\begin{abstract}
This community service is carried out as a form of the Tri Dharma of Higher Education, community service by raising the theme of the importance of maintaining and maintaining dental and oral health in children, pregnant women and the elderly. Dental and oral disease is one of the public health problems in Indonesia. This is based on reports of the high prevalence of sufferers of the disease, and is one of the top ten sequences of diseases that are most often complained of by the public. Dental and oral health is closely related to body health. The condition of the mouth and teeth that are not maintained will cause many problems and discomfort. In an effort to get good oral and dental health, awareness is needed to implement a healthy lifestyle by diligently brushing teeth properly and correctly. The purpose of this service is to provide understanding to the community, pregnant women and the elderly about the importance of maintaining and maintaining dental and oral health. The method of implementing community service with direct counseling techniques to the community. The results of the service, in general the counseling participants have an increased understanding of maintaining and maintaining dental and oral health. The conclusion of this service is the importance of continuous education and counseling to the community regarding the importance of maintaining and maintaining dental and oral health in children, pregnant women and the elderly.

Keyword: Counseling, Community Service, Oral Health
\end{abstract}

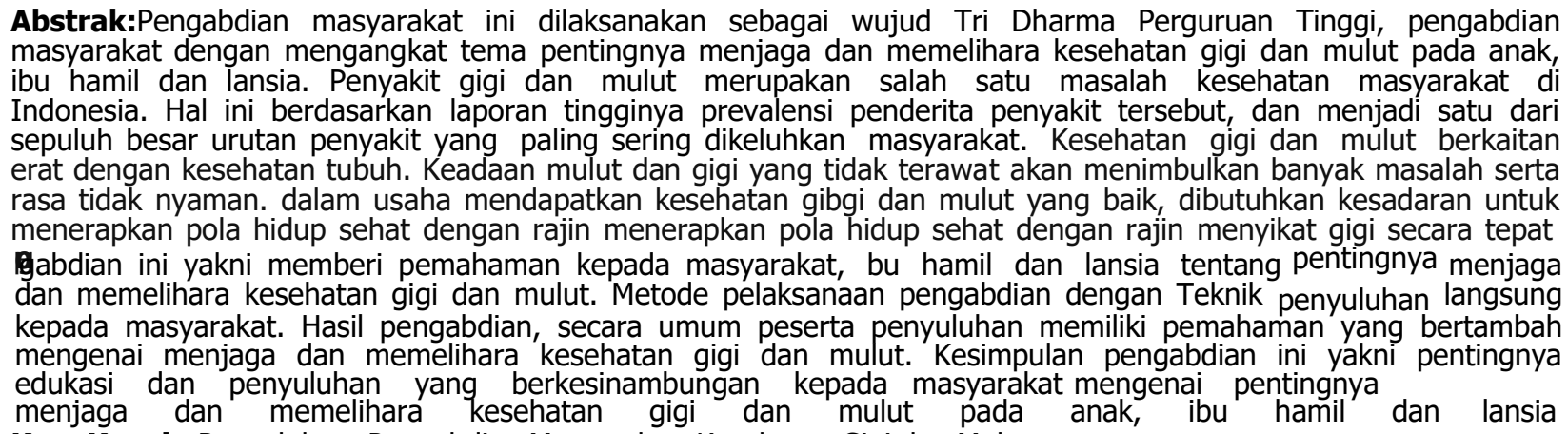
Kata Kunci : Penyuluhan, Pengabdian Masyarakat, Kesehatan Gigi dan Mulut

\section{PENDAHULUAN}

Puskesmas adalah sebuah organisasi kesehatan fungsional yang menyelenggarakan upaya kesehatan masyarakat dan upaya kesehatan perorangan tingkat pertama dengan mengutamakan upaya promotif dan preventif, guna mencapai derajat kesehatan masyarakat yang setinggi- tingginya di wilayah kerjanya ${ }^{1}$. Upaya kesehatan masyarakat yang dikembangkan dan pembinaan peran serta masyarakat dilakukan secara menyeluruh dan terpadu kepada segenap lapisan masyarakat yang berada di wilayah kerjanya ${ }^{2}$. Sebagai sebuah organisasi kesehatan fungsional yang menyelenggarakan pelayanan kesehatan masyarakat; diperlukan adanya sumber daya, metode, sarana dan prasarana agar tujuan yang ditetapkan dapat tercapai. Sumber daya yang ada, baik sumber daya manusia maupun finansial, adalah modal utama dalam mencapai tujuan Puskesmas.

Secara garis besarnya sumber daya manusia di Puskesmas terdiri atas tenaga medis (dokter, dokter gigi), paramedis (perawat, bidan, perawat gigi), dan tenaga penunjang lainnya (farmasi,sanitarian, penyuluh kesehatan). Dokter gigi dan perawat gigi merupakan dua tenaga kesehatan yang memegang peranan penting dalam memberikan upaya kesehatan gigi; baik upaya kuratif, preventif, dan promotif. Umumnya seluruh puskesmas melaksanakan kegiatan Yankesgi, baik dengan tenaga yang lengkap (dokter gigi dan perawat gigi) atau pun dengan tenaga tidak lengkap (hanya dokter gigi/ perawat gigi/tenaga kesehatan lainnya) ${ }^{3}$.

This is an open-access article under the CC BY 4.0 International

License

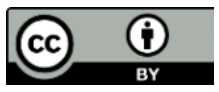

OPEN 
Kesehatan merupakan hak setiap warga Negara ${ }^{4}$, Untuk itu pemerintah melakukan pembangunan kesehatan yang bertujuan untuk meningkatkan kesadaran, kemauan dan kemampuan hidup sehat bagi setiap orang agar terwujud derajat kesehatan masyarakat yang optimal. Guna mewujudkan derajat kesehatan bagi masyarakat, diselenggarakan upaya kesehatan dengan pendekatan pemeliharaan, peningkatan kesehatan promotif, pencegahan penyakit (preventif), penyembuhan penyakit (kuratif) dan pemulihan kesehatan (rehabilitatif) yang dilaksanakan secara menyeluruh dan berkesinambungan, selain itu dari hasil Riskesdas 2013 diketahui bahwa masyarakat yang berperilaku menyikat gigi dengan benar (setiap hari menyikat gigi setelah makan pagi dan sebelum tidur malam) secara nasional sebesar $76,6 \%$, terdapat kenaikan dibandingkan dengan Riskesdas $2007(68,1 \%)^{5}$.

Penyakit gigi dan mulut merupakan salah satu masalah kesehatan masyarakat di Indonesia. Hal ini berdasarkan laporan tingginya prevalensi penderita penyakit tersebut, dan menjadi satu dari sepuluh besar urutan penyakit yang paling sering dikeluhkan masyarakat. Dari hasil Riskesdas 2007 diketahui bahwa prevalensi penduduk yang mempunyai masalah gigi dan mulut dalam 12 bulan terakhir adalah $23,4 \%$, dan terdapat $1,6 \%$ penduduk yang telah kehilangan seluruh gigi aslinya pada kelompok usia 10 tahun ke atas 6 .

Penyakit gigi dan mulut merupakan penyakit yang menyerang segala kelompok umur baik pada anak-anak sampai dewasa tak terkecuali pada kelompok lansia. Salah satu masalah kesehatan pada lansia adalah karies gigi dan penyakit periodontal. Hasil penelitian menunjukkan 95\% penderita bergigi dengan umur lebih 65 tahun mempunyai penyakit periodontal, dan $70 \%$ penderita lansia membutuhkan perawatan periodontal. Upaya yang dilakukan untuk mengatasi masalah penyakit gigi dan mulut pada lansia yakni dengan melakukan pendekatan dari tenaga kesehatan maupun dokter gigi tentang pentingnya kesehatan gigi dan mulut?.

Ibu hamil juga merupakan salah satu kondisi yang sering terkena penyakit gigi dan mulut. Tingginya prevalensi karies gigi pada ibu hamil pada trimester kedua dan ketiga dapat terjadi karena produksi dari hormon estrogen dan progesteron meningkat secara bertahap hingga bulan ke-delapan. Pada bulan akhir dari masa kehamilan, konsentrasi progesteron menjadi konstan tetapi produksi hormon estrogen terus meningkat. Pencegahan penyakit gigi dan mulut perlu dilakukan sedini mungkin. Saat ini pemerintah tengah menggalakkan program 1000 Hari Pertama Kehidupan, dengan tujuan mendampingi ibu hamil sejak hari pertama kehamilan. Kesehatan dan tumbuh kembang bayi dipantau dan dijaga agar maksimal, termasuk diantaranya kesehatan giginya kelak. Pemeriksaan dan kesehatan rongga mulut ibu hamil menjadi salah satu yang harus diperhatikan. Keberhasilan program tersebut memerlukan kerjasama semua pihak yang terkait agar terlahir generasi masa depan yang sehat, kuat dan unggul ${ }^{8}$.

Penyakit periodontal merupakan penyakit rongga mulut yang menempati urutan pertama dalam catatan buku rekor dunia tahun 2001 sebagai penyakit yang paling sering dialami manusia. Data penelitian Global Burden of Disease tahun 1990-2010 menunjukkan bahwa periodontitis berat (severe periodontitis) merupakan penyakit dengan prevalensi tertinggi keenam $(11,2 \%)$ dan diderita oleh sekitar 743 juta jiwa di dunia serta mengalami peningkatan prevalensi sebesar $57.3 \%$ dalam kurung waktu 10 tahun. Secara global, kerugian akibat berkurangnya produktivitas karena periodontitis berat di perkirakan mencapai 53,99 juta Dolar Amerika per tahunnya. Perkembangan pengetahuan mengenai penyakit periodontal terkait patogenesa, pemetaan bakteri, dan pemahaman mengenai peran host dalam patogenesa penyakit seta klasifikasi penyakit periodontal telah banyak dipelajari. Hubungan antara penyakit periodontal dengan kelainan sistemik juga sudah banyak diteliti. Namun dibalik kemajuan pengetahuan akan penyakit periodontal, prevalensi dari periodontitis terutama di Indonesia masih terbilang tinggi. Data RISKESDAS 2018 menunjukkan persentase kasus periodontitis di Indonesia sebesar 74,1\%9.

Media komunikasi, informasi, dan edukasi merupakan salah satu upaya untuk mencegah masalah kesehatan gigi dan mulut, mengubah perilaku kurang sehat menjadi sehat, meningkatkan pengetahuan dan kesadaran, sehingga ikut berpartisipasi serta aktif dalam meningkatkan derajat kesehatan gigi dan mulut di masyarakat ${ }^{10}$.

This is an open-access article under the CC BY 4.0 International License

(c) Idea PengabdianMasyarakat (2022)

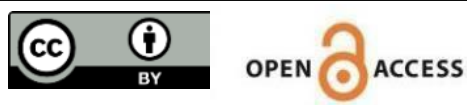


Puskesmas Parangloe mengalami kekosongan tenaga medis dokter gigi sejak tahun 2017, sehingga kegiatan seperti penyuluhan maupun tindakan perawatan gigi dan mulut menjadi sangat terbatas. Berdasarkan keterbatasan dokter gigi untuk melakukan kegiatan tersebut , maka kami berencana untuk melakukan kegiatan pengabdian berupa penyuluhan dengan menyesuaikan program PKM Parangloe yang bertujuan untuk memberikan pengetahuan mengenai pentingnya menjaga kebersihan kesehatan gigi dan mulut kepada masyarakat. Untuk kegiatan ini kami akan melakukan di desa Lanna sebagai prototype kegiatan untuk kegiatan yang lebih luas lagi. Pada kegiatan ini akan dilaksanakan penyuluhan ke masyarakat desa Lanna dan bekerja sama dengan PKM parangloe dalam bentuk video dan pemberian leaflet tentang pemeliharaan kesehatan gigi dan mulut.

\section{METODE PELAKSANAAN}

Penyuluhan kesehatan ini kami bagi dalam beberapa metode pelaksanaan yakni melakukan penyuluhan menjaga kesehatan gigi dan mulut melalui metode pemberian nasihat, video dan flipchart serta pemberianDental Kit danleaflet.

\section{Tahap 1 Persiapan}

Kunjungan pertama dilakukan pada hari Senin 2 September 2021 pukul 09.30 WITA di Puskesmas Parangloe kemudian dilanjutkan kunjungan kedua di Kantor Kelurahan Lanna untuk berkoordinasi perihal menyepakati jadwal kunjungan selanjutnya untuk melaksanakan kegiatan pengabdian.

\section{Tahap 2 Pelaksanaan}

Pembagian Kuisioner (Pre-Test)

Kegiatan ini dilakukan pada hari Kamis, 9 September 2021 Pukul 10.00 WITA di Aula Kantor Kelurahan Lanna. Kegiatan penyuluhan ini dihadiri oleh masurakat Kelurahan Lanna Tonasa serta perwakilan dari Puskemas PArangloe. Kegiatan diawali dengan pemberian kuisiner (pre-test) untuk menilai pengetahuan para peserta mengenai menjada dan memelihara kesehatan gigi dan mulut.

Kegiatan Penyuluhan

Kegiatan Penyuluhan dilakukan di Aula Pertemuan Kelurahan Lanna dengan tetap mematuhi protokol kesehatan dengan menggunakan masker. metode yang diberikan berupa nasehat dan menggunakan video cara menyikat gigi dengan baik dan benar, sikat gigi 2 kali sehari setelah sarapan dan sebelum tidur, periksa gigi ke dokter gigi 6 bulan sekali, gigi yang berlubang dirawat (ditambal), perbanyak makan buah/sayur, serta banyak minum air putih. Setelah penyuluhan kemudian di buka sesi tanya jawab untuk menjawab pertanyaan-pertanyaan yang ditanyakan oleh para peserta.

\section{Tahap 3 Pemberian Kuesioner II}

Post-Test ini dilakukan untuk menilai apakah ada perubahan mengenai pengetahuan masyarakat mengenai menjaga dan memelihara kesehatan gigi dan mulut

Pemberian Dental Kit dan Leaflet

Pembagian Dental Kit dan Leaflet dilakukan pada hari yang sama, hal ini bertujuan agar masyarakat melihat langsung melalui media yang dibagikan mengenai pentingnya menjaga kesehatan gigi dan mulut.

Post-Test II ini dilakukan 2 minggu setalah Post Test I, untuk menilai apakah ada perubahan mengenai pengetahuan orang tua murid dan guru mengenai kesehatan gigi dan mulut berimplikasi kepada meningkatnya kepedulian orang tua kepada kesehatan gigi dan mulutnya

This is an open-access article under the CC BY 4.0 International License

(c) Idea Pengabdian Masyarakat (2022)

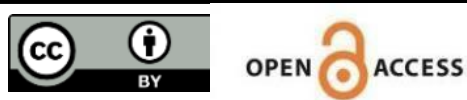




\section{HASIL DAN PEMBAHASAN}

Penyuluhan Kesehatan Gigi dan Mulut

Kegiatan ini bertujuan memberikan pengetahuan kepada masyarakat tentang pentingnya menjaga dan memelihara kesehatan gigi dan mulut apada anak, ibu hamil dan lansia.

Pembagian Leaflet

Pembagian leaflet bertujuan agar masyrakat memahami melalui media gambar tentang pentingnya menjaga kesehatan gigi dan mulut pada anak, ibu hamil dan lansia serta dampak yang terjadi apabila tidak menjaga dan memelihara kesehatan gigi dan mulut

Tabel 1

\begin{tabular}{|c|c|c|}
\hline No & Nama Kegiatan & Keterangan \\
\hline 1 & Pengisian Kuisoner Pre dan Post & Terlaksana \\
\hline 2 & Penyuluhan Kesehatan Gigi dan Mulut & Terlaksana \\
\hline 3 & Pemberian Dental Kit dan Leaflet & Terlaksana \\
\hline
\end{tabular}
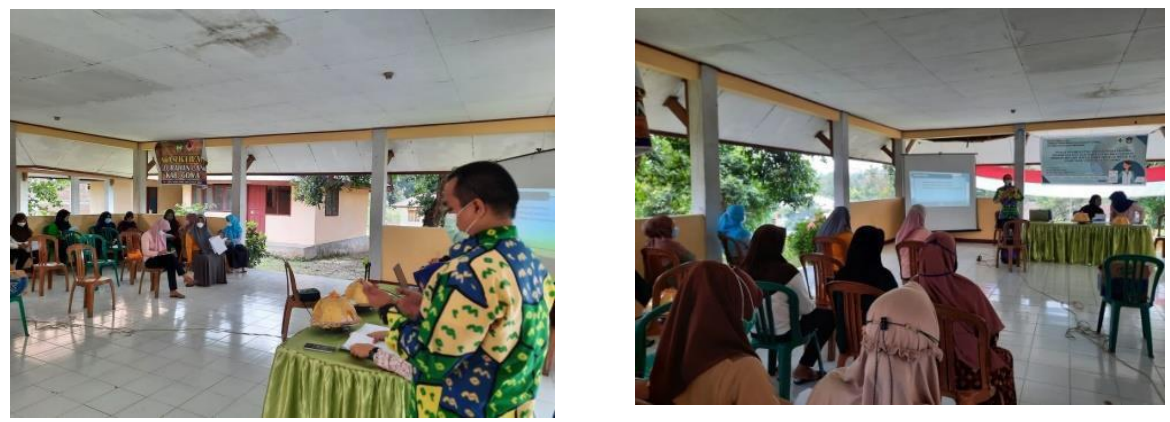

Gambar 1. Pengisian Kuisioner (Pre-Test), Gambar 2. Penyuluhan mengenai "Pentingnya Menjaga dan Memelihara Kesehatan Gigi dan Mulut pada anak, Ibu hamil dan lansia"

\section{KESIMPULAN}

Kegiatan penyuluhan kesehatan kepada masyarakat kelurahan Lanna ini sangat penting dilakukan, mengingat kesadaran untuk menjaga kesehatan gigi dan mulut masih sangat kurang, pengabdian masyarakat yang dilakukan oleh Dosen adalah upaya membantu pemerintah dalam mensukseskan kebijakan serta bentuk pengimplementasian perguruan tinggi dalam melakasanakan Tri Dharma Perguruan Tinggi

\section{UCAPAN TERIMAKASIH}

Terimakasih Kepada Pemerintah Kabupaten Gowa, Pemerintah Kelurahan Lanna, dan Puskemas Parangloe dan TIM Dosen dan mahsiswa/i serta LPkM Universitas Muslim Indonesia.

\section{DAFTAR PUSTAKA}

1. Kemenkes RI. Peraturan Menteri Kesehatan Republik Indonesia Nomor 75 Tahun 2014. Jakarta; 2014.

2. Azrul Azwar. Pengantar Administrasi Kesehatan. 3rd ed. Jakarta: Binarupa Aksara; 1996.

3. Anorital A, Muljati S, Andayasari L. Gambaran Ketersediaan Tenaga dan Upaya Pelayanan Kesehatan Gigi di Puskesmas (Analisis Lanjut Riset Fasilitas Kesehatan 2011). Bul Penelit Kesehat. 2016;44(3):197-204.

This is an open-access article under the CC BY 4.0 International License

(c) Idea Pengabdian Masyarakat (2022)

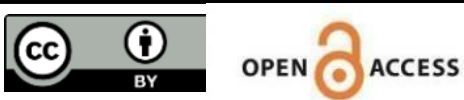


4. Badan Penelitian dan Pengembangan Kesehatan, Departemen Kesehatan RI. Riset Kesehatan Dasar. Jakarta; 2008.

5. Badan Penelitian dan Pengembangan Kesehatan, Kementrian Kesehatan RI. Laporan Hasil Riset Fasilitas Kesehatan. Jakarta; 2012.

6. Andayasari L. Analisis Hubungan Fasilitas Pelayanan Kesehatan Gigi dan. J Biotek Medisiana Indones. 2014;85-100.

7. Ermawati T, Sari DS, Yuliana MDA. Upaya Peningkatan Kesehatan Gigi dan Mulut pada Lansia (Improving the Oral Health of Elderly). Fakultas Kedokteran Gigi, Universitas Jember; 2015.

8. Soulissa AG. Hubungan Kehamilan dan Penyakit Periodontal. 2014;63(3):71-7.

9. Badan Penelitian dan Pengembangan Kesehatan, Kementrian Kesehatan RI. Laporan Nasional Riskesdas 2018. Jakarta: Lembaga Penerbit Badan Penelitian dan Pengembangan Kesehatan; 2019.

10. Saurina N. Pengembangan Media Pembelajaran untuk Anak Usia. J IPTEK. 2016;20(1):95-108. 